\title{
EDITORIAL
}

\section{Continuing medical education across Europe: the role of EBAP and the ERS in facing the challenges of life- long learning}

\author{
M. Gaga*, T. Séverin* and R. Stevenson
}

I $\mathrm{n}$ medicine, good professional training and education are pivotal, and these include initial medical studies and, even more importantly, continuing medical education (CME). Learning on the job is an important and indisputable part of continuing medical education but, in itself, it is not enough. Attending meetings, reading journals and books, seeking expert advice and, in recent years, getting information from web-based sources are the usual ways by which doctors learn and keep up to date. However, because CME is not only necessary for the physician but is also associated with better patient care, it should be done in a structured and validated way. This concept is currently being incorporated in the legislation governing medical practice in many countries. From this has stemmed the need for CME credits and associated accreditation processes. Initially, CME accreditation required only attendance at meetings but, in recent years, CME journals and books, as well as various other forms of accessible and interactive e-learning activities, have been added. All these now come under the heading of $\mathrm{CME}$, which has been defined by the Accreditation Council for Continuing Medical Education in the USA as "educational activities that serve to maintain, develop or increase the knowledge, skills and professional performance and relationships a physician uses to provide services for patients, the public or the profession".

On a European level, the European Accreditation Council for Continuing Medical Education (EACCME) was set up in 1999 by the European Union of Medical Specialties (UEMS). Initially, European CME was accredited jointly by EACCME and the national accreditation authorities of the countries which hosted educational events. In 2001, the UEMS Sections of Cardiology and Pneumology asked their respective European scientific societies (European Society of Cardiology and European Respiratory Society) to provide financial support for CME accreditation and the European Boards for Accreditation in Cardiology and Pneumology (EBAC and EBAP, respectively) were formed.

\footnotetext{
*Asthma Centre and 7th Respiratory Medicine Dept, Athens Chest Hospital, Athens, Greece. \#European Respiratory Society, Lausanne, Switzerland. "European Board for Accreditation in Pneumology (EBAP), Glasgow, UK.
}

CORRESPONDENCE: M. Gaga, Asthma Centre and 7th Respiratory Medicine Dept, Athens Chest Hospital, Sotiria Hospital, 152 Mesogion Avenue, Athens, 11527, Greece. E-mail: mgaga@ med.uoa.gr
There are certain general rules that apply to educational interventions that can be CME accredited. The content should be aimed at the target audience, be relevant to their needs and lead to improved skills and knowledge and even changes in practice attitudes or prescribing. And of course, the content should be unbiased. This introduces the need for accrediting the provider as well as the educational intervention. As European physicians, we face an additional challenge due to the heterogeneity of educational curricula and training programmes across Europe. Some training programmes last 4 yrs, others last $6 \mathrm{yrs}$, some include sleep or oncology but others do not, some countries require an exit exam and others do not. Although the European Respiratory Society (ERS) and the ERS School have taken an important step forward and established Harmonised Education in Respiratory Medicine for European Specialists (HERMES), the initiative for harmonising education that led to the production of a European curriculum in adult respiratory medicine [1, 2], as well as a syllabus for paediatric respiratory medicine [3], actual implementation of this initiative throughout Europe will be a lengthy process. Therefore, CME providers and EBAP, as a European accreditation body, must be aware of this heterogeneity and take into account the different backgrounds and needs of the target audience when setting up and/or accrediting an international CME programme. To complement this initiative aimed mainly at basic specialty training, the ERS has also pushed for a structured, efficient and prompt accreditation process on a European level, which has led to a reformed EBAP.

EBAP has recently been reconstituted and now operates under supervision of a management council composed of members nominated by the Forum of European Respiratory Societies and the ERS. The new EBAP liaises with UEMS/EACCME in providing accreditation for CME events and other educational packages, but it is independent in its assessments. The EBAP is committed to improving the quality of European CME and to change the emphasis in educational interventions and CME accreditation from teaching to learning with consequent beneficial effects on doctors' practice. This follows the results of studies suggesting that the provision of standard CME has had little effect on clinical outcomes. In particular, there is evidence that traditional didactic teaching, as delivered by lectures, has very little impact on clinical behaviour [4]. Conversely, different modalities of CME, such as small group 
interactive sessions, web-based interactive learning, journalbased CME linked with multiple choice questions and case/ problem-based learning have been shown to affect outcomes [5-7]. It is now accepted that CME should primarily be relevant to practice improvement.

The new EBAP is currently developing detailed and rigorous criteria to encourage CME providers to create educational material that will influence clinical practice. In liaising with providers, EBAP is exploring the different modalities of education and the means of assessing their effects on learning. Doctors should be asked to indicate that they have benefited from an educational experience before being awarded CME credits. The premise must be that CME should augment those qualities that contribute to "best practice". Of these, three may be specified: 1) knowledge, where factual transfer is reinforced by repetition or some other incentive for retention, such as problem solving or case discussions; 2) experience, including manual skills delivered by CME in surrogate forms, such as simulation and hands-on sessions; and 3) attitude, which includes not only motivation to perform well professionally, but also diagnostic curiosity and a degree of healthy scepticism about ill-founded assumptions. Providers must be encouraged to consider these qualities and must recognise that emphasis should be more on learning than on teaching.

For the accreditation process, EBAP has a number of reviewers who are experts in various fields of pulmonology. Each request for accreditation to EBAP should include a needs assessment, the full programme and information on the target audience and the aim of the educational intervention. Each application is evaluated by at least two reviewers. The content, the time allowed for interactivity, the integrity of the provider, the quality of the speakers/authors, the relevance of educational questions and the inclusion of participant feedback are important points considered during the evaluation. The reviewers are particularly required to satisfy themselves that the educational material is not biased by commercial interests of the pharmaceutical industry.

\section{WHAT DOES EBAP ACCREDIT?}

1) Live events with clear educational value, such as: congresses, courses, and clinical and research seminars. EBAP accreditation is not competitive with, but complementary to, national CME accreditation.

2) E-learning, which includes HTML-based courses, webcasts and live online conferences (preferably interactive), in addition to educational CD-ROMs.

3) CME articles with clear educational aims and relevant test questions (four per article).
WHAT ARE THE BENEFITS OF EBAP ACCREDITATION?

For physicians: EBAP accreditation means that physicians from one country can attend a CME programme in another, with the expectation that their credits will be recognised by their own national accreditation authority. Physicians can be assured that EBAP-accredited CME programmes have been carefully assessed according to European quality standards for CME activities and thus provide a high-quality programme of scientific content.

For CME providers: the accredited CME activity is distinguished from other potential educational activities because its quality has been confirmed by an impartial board of specialists widely recognised in the field of pneumology. EBAP-accredited programmes will attract a greater number of participants from international and national institutions, providing a broader wealth of knowledge at CME events.

The website of the EBAP can be found at www.ebap.org/

We hope that the new EBAP will contribute to the quiet revolution that is taking place in $\mathrm{CME}$ provision, accreditation and effectiveness and we firmly believe that life-long learning should be exciting, challenging and rewarding.

\section{STATEMENT OF INTEREST}

None declared.

\section{REFERENCES}

1 Loddenkemper R, Séverin T, Haslam P. European curriculum recommendations for training in adult respiratory medicine: crossing boundaries with HERMES. Eur Respir J 2008; 32: 538-540.

2 Loddenkemper R, Séverin T, Eiselé J-L, et al. HERMES: good reasons for harmonising education and training in respiratory medicine. Eur Respir J 2006; 28: 470-471.

3 Gappa M, Paton J, Baraldi E, et al. Paediatric HERMES: update of the European Training Syllabus for Paediatric Respiratory Medicine. Eur Respir J 2009; 33: 464-465.

4 Davis D, O'Brien MA, Freemantle N, et al. Impact of formal continuing medical education: do conferences, workshops, rounds, and other traditional continuing education activities change physician behavior or health care outcomes? JAMA 1999; 282 867-874.

5 Davis DA, Thomson MA, Oxman AD, et al. Changing physician performance. A systematic review of the effect of continuing medical education strategies. JAMA 1995; 274: 700-705.

6 Mansouri M, Lockyer J. A meta-analysis of continuing medical education effectiveness. J Contin Educ Health Prof 2007; 27: 6-15.

7 Johns Hopkins University. Effectiveness of Continuing Medical Education. Baltimore, John Hopkins University, 2007. Available from: www.ahrq.gov/downloads/pub/evidence/pdf/cme/cme.pdf 